\title{
Circulation patterns in a channel reef-lagoon system, Ouano lagoon, New Caledonia
}

\author{
$\operatorname{Damien~Sous~}^{(a, b)}$, Cristele Chevalier ${ }^{(b, a)}$, Jean-Luc Devenon ${ }^{(b, a)}$, Jean Blanchot ${ }^{(b, a)}$, Marc Pagano ${ }^{(b, a)}$ \\ (a) Université de Toulon, CNRS/INSU, IRD, MIO, UM 110, 83957 La Garde Cedex, France \\ (b) Aix-Marseille Université, CNRS/INSU, IRD, MIO, UM 110, 13288 Marseille cedex, France
}

\begin{abstract}
This paper reports on two three-months field experiments carried out in the Ouano lagoon, New Caledonia. This channel-type lagoon, exposed to meso-tides, south pacific swells and trade winds, has been monitored thanks to a network of currents profilers to understand the dynamics of the lagoon waters. Four typical circulation patterns have been identified, covering all together more than $90 \%$ of the survey period. These patterns are mainly driven by the waves and wind features. In particular, obliquely incident waves or strong winds blowing over a sufficient period are able to reverse the typical circulation pattern. The analysis of the vertical structure of the currents through passages shows the regular presence of a nearly linear vertical shear within the water column.
\end{abstract}

\section{Introduction}

Coral reefs are both invaluable and endangered living systems in the nearshore areas of tropical regions. They provide a unique habitat for countless species as well as a natural and efficient protection against erosion process and submersion events induced by storms or tsunamis (Fernando et al., 2005). Unfortunately, the reef colonies and all their benefits for biological and human populations are threatened by the combined effects of the increasing anthropic pressure and the climate change (sea level rise, acidification, warming, etc).

The hydrodynamical functioning of reef-lagoon systems remains a challenging task for coastal oceanographers. It is, from a physical point of view, a striking example of interacting processes over a wide spatio-temporal range but also a fundamental step for the characterization of the biogeochemical processes which finally govern the health and resilience of the ecosystema (Carassou et al., 2010; Szmant, 2002).

Reef-lagoon systems are potentially exposed to a wide set of physical forcings such as tides, waves, wind, coastal currents, rainfalls, river discharges and evaporation which affect the dynamics and the quality of lagoon waters. Density-driven currents have been observed between lagoon and ocean (Atkinson et al., 1981), but the overwhelming trend is that tides, waves and wind are, by far, the main drivers of lagoon circulation and water renewal in most configurations (Wolanski et al., 1993; Kraines et al., 1998, 1999; Tartinville and Rancher, 2000; Andréfouët et al., 2001; Kench and McLean, 2004; Angwenyi and Rydberg, 2005; Hench et al., 2008; Lowe et al., 2009; Taebi et al., 2011; Hoeke et al., 2013; Chevalier et al., 2014, 2015). The tidal cycles have a direct effect on the lagoon water : the lagoon fills during the flow and empties during the ebb, inducing the so called tidal ellipses representing periodically rotating currents. This basic scheme can be significantly complicated by the presence of complex lagoon bathymetry with multiple openings and 
passages toward the open ocean and the neighbouring lagoons. The dynamics of the lagoon waters, the mixing, exchanges and renewal processes as well as the residence time (Delhez et al., 1999; Monsen et al., 2002; Delhez et al., 2014) are thus dramatically dependent on the lagoon geometry (atoll, barrier reef or fringing reef) and volume and the passage cross-sections. The fluctuations of the still water level, mainly due to tides, induces modifications of both lagoon volume and channels/passages sections. Furthermore, they strongly affect the wave breaking process over the reef which determines in a large part, i.e. as soon as waves break on the reef top, the cross-reef fluxes. This explains why lagoon circulation studies must take into account the wave effect, and also justifies the great amount of research efforts spent to understand wave transformation over reefs and related currents (Lowe et al., 2005; Monismith, 2007; Lugo-Fernandez et al., 1998; Hearn, 1999; Gourlay and Colleter, 2005; Bonneton et al., 2007). The main physical processes during the wave propagation, which are now fairly well understood, include refraction, reflection and shoaling on the outside reef slope (Kraines et al., 1998; Symonds et al., 1995; Gourlay, 1996a,b; Massel and Gourlay, 2000), bathymetric breaking occuring generally before the reef top (Hardy and Young, 1996; Hearn and Parker, 1988; Kraines et al., 1998), harmonic transfers toward infragravity (IG) waves (Pomeroy et al., 2012; Van Dongeren et al., 2013) but also possibly to higher frequency (superharmonics) waves (Chevalier et al., 2015; Masselink, 1998), dissipation by friction and interaction with co- or counter-current (Roberts and Suhayda, 1983). The relative importance of each process during the wave propagation toward the shore is controlled by the offshore wave features, the bathymetry, the mean water level and slope and the reef roughness.

This rich literature shows that a great research effort has been engaged during the last two decades to understand the bulk dynamics of reef-lagoon systems exposed to a set of time-varying, and often interacting, forcings. In this context, the present study aims to present and analyse a long-term field survey of the Ouano lagoon, New Caledonia. More than six months of current measurements have been performed in strategic points of the system to better understand the lagoon interaction with the open ocean and the neighbouring lagoons. The first section of the paper is dedicated to the presentation of the studied site and the experimental setup. The second section summarizes the results in order to identify the main drivers of the lagoon dynamics and the most typical circulation patterns, with a subsection devoted to the analysis of the vertical structure of the currents. The third section discusses the observed mechanisms in a more general context, including biogeochemical issues.

\section{Field site and experiments}

\subsection{Field site}

The New Caledonia archipelago hosts one of the largest reef structures worldwide, partly inscribed to the UNESCO World Heritage List in 2008 (GRENZ et al., 2013). The study site is the Ouano lagoon (Fig. 1), located on the south-west coast. It is an approximately $30 \mathrm{~km}$ long, $10 \mathrm{~km}$ wide and $10 \mathrm{~m}$ deep channeltype lagoon (Chevalier et al., 2015) mostly exposed to south pacific swell waves, trade winds and meso-tidal fluctuations.

The lagoon is directly opened to ocean through two reef-openings in the north-west section of the reef barrier. The southern opening is about $1 \mathrm{~km}$ wide and 10-20m deep (the Isié reef opening) while the northern (the Ouarä̈reef opening) is the deepest, down to $-60 \mathrm{~m}$ and $1.5 \mathrm{~km}$ wide. The lagoon is connected to northern 


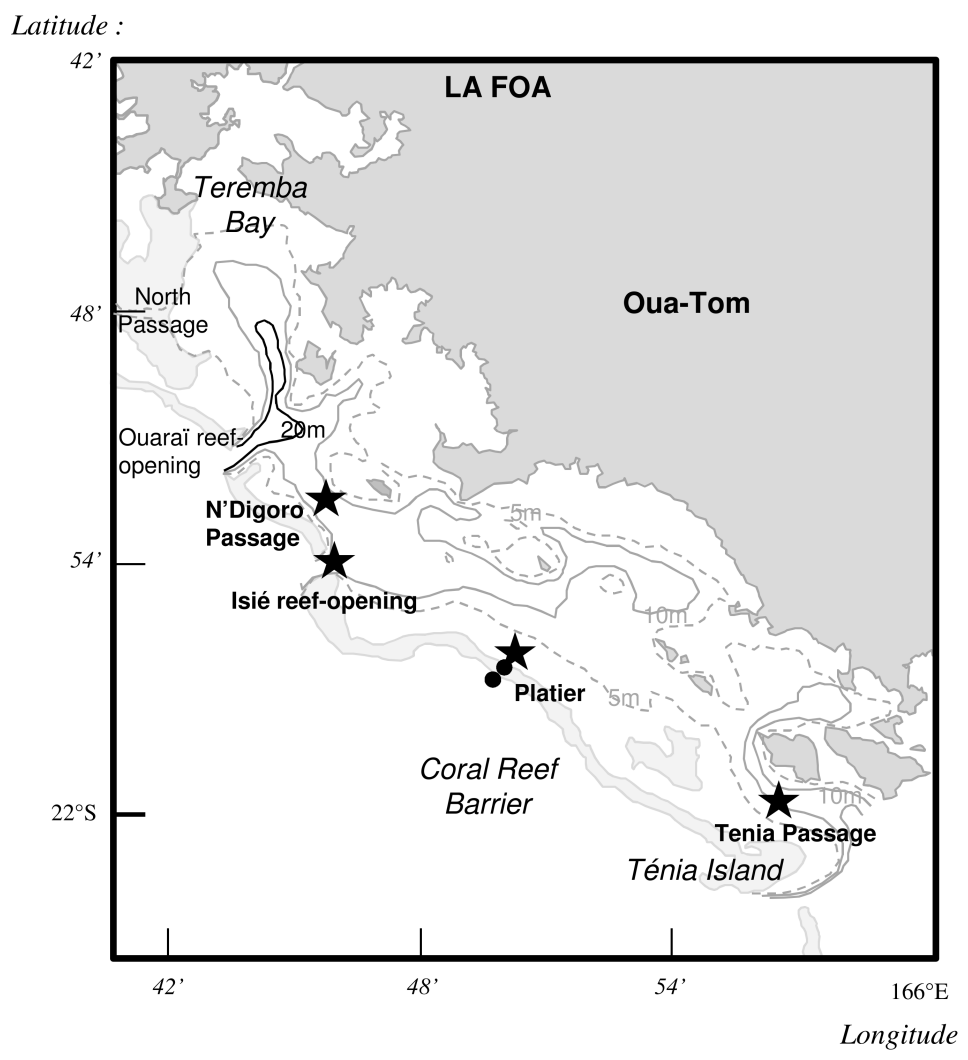

Figure 1: Top view of the Ouano lagoon system. Black dots and stars represent pressure sensors and velocity profilers locations, respectively.

and southern lagoons by two passages, one toward north and one toward south. The northern passage is about $5 \mathrm{~m}$ deep while the south passage (the Tenia passage) is $10-15 \mathrm{~m}$ deep. Note that this latter is close to a further south reef-opening. At high tide, the coral reef barrier is fully submerged, whereas at low tide it can be partly emerged depending on tide and wave conditions.

In the present study, the instrumentation is focused to a well-defined lagoon system extending from the Tenia passage to the N'Digoro passage where the lagoon topography is rather simple with a limited number of openings (see Fig. 1). This simple geometry allows that the physics of the problem can be more easily understood before extending to more complex systems. In this part of the Ouano lagoon, the reef barrier is $25 \mathrm{~km}$ long and only opened at the Isié reef opening. The total volume of the considered portion of the lagoon is then about $1.310^{9} \mathrm{~m}^{3}$.

\subsection{Field experiments and methods}

Two field campaigns have been carried out in the Ouano lagoon : the first in 2013 from August 28 to December 4 and the second in 2015, from January 10 to April 15. A first analysis of the 2013 experiment has focused on the parameterization of cross-reef fluxes in a coastal circulation numerical model (Chevalier et al., 2015). The 2013 data is here further analysed and combined with the 2015 experiment to provide a general view of the circulations patterns in the Ouano lagoon, over two different seasons including a wide 


\begin{tabular}{|c|c|c|c|c|c|c|c|c|}
\hline \multicolumn{2}{|c|}{ Site } & \multicolumn{7}{|c|}{ Profiler Parameters } \\
\hline Location & Depth & Sensor & Samp.-Aver. & Vert. res. & 1st Bin & Pings/ens & Time/Ping & SD \\
\hline & $(\mathrm{m})$ & $(\min -\min )$ & $(\mathrm{m})$ & $(\mathrm{m})$ & & & $(\mathrm{s})$ & $(\mathrm{cm} / \mathrm{s})$ \\
\hline \multicolumn{9}{|c|}{2013} \\
\hline N'Digoro & $14.84 \pm 0.05$ & Rdi $300 \mathrm{KHz}$ & $10-1$ & 1.5 & 3.73 & 100 & 0.55 & 1 \\
\hline Isié & $16.80 \pm 0.05$ & Rdi $300 \mathrm{KHz}$ & $10-1$ & 1.5 & 3.73 & 100 & 0.55 & 1 \\
\hline Platier & $3.53 \pm 0.05$ & Sontek $3 \mathrm{MHz}$ & $10-1.5$ & 0.25 & 0.45 & asap & $\mathrm{nc}$ & nc \\
\hline Tenia & $13.89 \pm 0.05$ & Rdi $300 \mathrm{KHz}$ & $10-1$ & 1.5 & 3.73 & 100 & 0.55 & 1 \\
\hline \multicolumn{9}{|c|}{2015} \\
\hline N'Digoro & $15.71 \pm 0.05$ & Rdi $300 \mathrm{KHz}$ & $10-1$ & 1.5 & 3.73 & 100 & 0.55 & 1 \\
\hline Isié & $16.19 \pm 0.05$ & Rdi $300 \mathrm{KHz}$ & $10-1$ & 1.5 & 3.73 & 100 & 0.55 & 1 \\
\hline Platier & $3.31 \pm 0.05$ & Sontek $3 \mathrm{MHz}$ & $10-1.5$ & 0.25 & 0.45 & asap & $\mathrm{nc}$ & nc \\
\hline Tenia & $14.20 \pm 0.05$ & Rdi $300 \mathrm{KHz}$ & $10-1$ & 1.5 & 3.73 & 100 & 0.55 & 1 \\
\hline
\end{tabular}

TABLE 1: Current profilers characteristics during the field experiments (asap : as soon as possible - ping per ensemble, $n c$ : no theoretical value calculated by Sontek).

range of wave, wind and tide conditions.

Four current profilers (ADCP) were deployed during the experiment to provide data on temporal variability of current velocity and direction along vertical profiles. Three Acoustic Doppler Current Profilers (ADCP) were deployed (Fig. 1) in lagoon passages (N'Digoro and Tenia) and reef-opening (Isié). An additional profiler was deployed in shallower area at the onshore end of the reef flat (the Platier site) to measure the cross-reef exchanges between lagoon and ocean. Mooring depths and profilers parameters are summarized in table 1 .

Wave dynamics on the outside reef slope was measured thanks to autonomous pressure sensors OSSI Wave Gauge (5Hz sampling frequency) and RBR Duo (1Hz sampling frequency) for the first and second campaigns. Pressure sensors are fixed on the bottom, at immersion depths 14.4 and $12 \mathrm{~m}$ for the first and second experiments, respectively. Linear theory is used to estimate free surface oscillations and related significant wave height $H_{s}$ from pressure measurements at the bottom over 30-min time window. Meteorological data (wind, pressure and humidity) were provided by the Tontouta airport station. Offshore wave data used to relate for both 2013 and 2015 campaigns the lagoon circulation with wave features, including $H_{s}^{w w 3}$ significant wave height, $T_{p}^{w w 3}$ the peak period and $\theta^{w w 3}$ the mean wave direction were computed by WAVEWATCH III model version 4.04. In addition, statistical analysis on the wave climate have been performed on IOWAGA 1994-2012 numerical data (CFSR forcing).

Section 3.5 presents an analysis of the vertical structure of currents. A quantitative estimation of the vertical shearing over the water column is provided by the calculation of the horizontal component of the vorticity vector $\partial U / \partial z$. The vorticity is first calculated for each bin and then depth-averaged over the water column. The vertical shear of current is generally quite linear for main velocity components at Isié, Tenia and N'Digoro sites, so that the depth-averaged vorticity can be generally considered as a relevant indicator. Along the reef (Platier site), the vertical structure of the current is usually much more complex which can not be simply analysed in terms of depth-averaged quantities and will not be discussed here. 

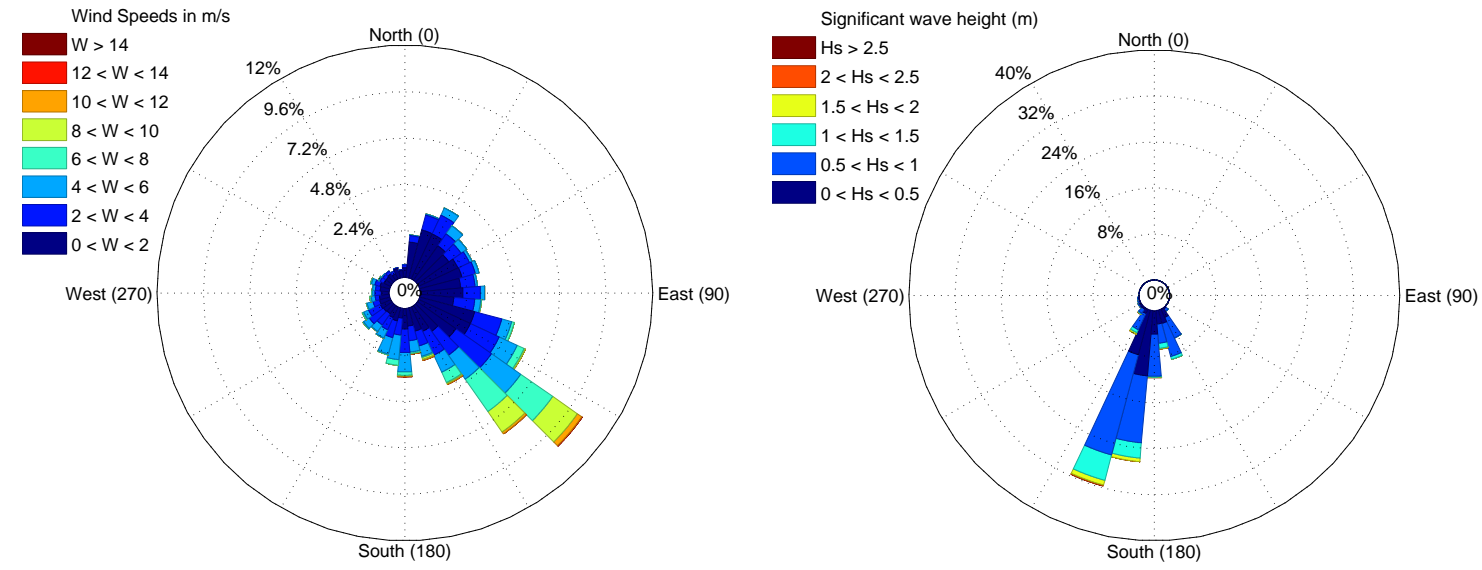

Figure 2: Wind rose (left) and wave rose (right) for cumulated data of both 2013 and 2015 experiments.

\subsection{Field conditions}

In most reef-lagoon systems, water circulation is mainly controlled by fluxes through passages, reef opening and above the immersed part of the coral barrier in response to external forcings, such as tides, waves and wind (Bonneton et al., 2007; Gourlay and Colleter, 2005; Roberts et al., 1975; Roberts and Suhayda, 1983). In the considered lagoon, the main driver is the tide, as demonstrated for instance by the spectral analysis shown in Fig 3 or the periodic oscillations of velocities observed in Figs. 4 or 5 . In this paper, a particular attention is paid on the role played by the other main forcings of the lagoon system, i.e. waves and wind, through the study of five parameters : the incoming wave height $H_{s}$, peak period $T_{p}$ and direction $\theta_{w w 3}$ and the wind magnitude $W$ and direction $\theta_{w}$. Rainfalls have been sparse on the studied periods and are neglected.

Statistical features of waves and wind over the cumulated data (2013 and 2015 experiments) are summarized in the wind and wave roses shown in Fig 2. Wind measurements performed at the nearby Tontouta airport station revealed the typical wind pattern observed during the experiments. Trade winds are modulated by thermal breeze and guided by the mountainous topography of New Caledonia. The dominant pattern is clear : strong winds always blow from the south east and almost no winds are coming from the north-west sector. Daily variations are observed in Figs. 4 and 5. Winds are minimal during nights (lower than $1 \mathrm{~m} / \mathrm{s}$ ) and nearly offshore (north-west to north). They increase during the day while clockwise rotating and blowing from the east, then south and finally west before slowing down in late afternoon. This typical trend shows a slight seasonal variation is observed when comparing Figs. 4 and 5, the wind tends to be stronger during the spring. The mean and maximal measured values are 2.5 and $12.4 \mathrm{~m} / \mathrm{s}$ for the 2013 experiment and 2.9 and 12.2 for the 2015 experiments.

The wave distribution shown in Fig. 2, right plot, shows that waves are coming from a quite narrow sector between 140 and $215^{\circ}$. The main peak period is $11.7 \mathrm{~s}$ which indicates the dominance of long swell waves. Mean and maximal wave heights are about 0.96 and $2.74 \mathrm{~m}$ for the 2013 experiment, and 1.22 and $3.79 \mathrm{~m}$ for the 2015 experiment. The strong wave events $\left(H_{s}>1.5 \mathrm{~m}\right)$ are generally associated to direction about $200^{\circ}$, with a noticeable exception around March 14, 2015 with a more south-eastern swell event. 


\section{Results}

\subsection{Overview}

Let us first have a look on an overall directional and spectral analysis of the measured currents which allows to define the variables used hereinafter. Figure 3 depicts direction probability and energy spectrum for depth-averaged current at each site. As expected in the presence of strong bathymetric constraints, the current are well-channelized in the reef passages and opening during the filling-emptying cycles of the lagoon induced by the tide. At the Platier (reef) site, a larger directional spread is observed, but a main tendency toward north is clearly observed. A more detailed analysis of current dynamics is presented hereinafter, but this result allows to define, for each site, a projection axis along the main flow direction to obtain the main and transverse components called $U$ and $V$ respectively. The sign convention is that an inward lagoonentering current is related to a positive value of the main component. In most cases, the analysis will be performed on the main component $U$ while the tranverse component can be neglected. The only exception is the Platier site for which the transverse component $V_{\text {platier }}$ can be important.

The spectral analysis of depth-averaged currents presented in Fig. 3 (right plot) demonstrates the strong influence of tidal components in the velocity signal : by order of decreasing importance M2 (12h25) combined with S2 (12h), K1 (23h56), M4 (6h12) and M6 (4h08). As described by Chevalier et al. (2015), the amplitude of water level variation shows the prevalence of the semi-diurnal and diurnal tides M2, S2 and K1 which determine about $97 \%$ of the signal. To remove the influence of tides on the velocity measurements, currents can be either day-averaged or detided. The former will be denoted with the superscript ${ }^{d a}$ in the following. The latter, identified with the superscript ${ }^{d t}$, are obtained by applying band-stops filters to the current data around the three dominant harmonics frequencies : $f=2.28 .10^{-5} \mathrm{~Hz}(\mathrm{M} 2 / \mathrm{S} 2), f=1.16 .10^{-5} \mathrm{~Hz}(\mathrm{~K} 1)$ and $f=4.47 .10^{-5} \mathrm{~Hz}$ (M4). As exposed in the following, day-averaged currents are the most relevant variable to identify the circulation pattern at the lagoon scale while detided values will mainly be used to highlight the timelag between forcings evolution and currents response.

One notes that the M4 component is more significant for current than for free surface spectra (dashed line in Fig. 3). However, rather than a real M4 signature, this observation reveals the modulation of cross-reef currents at twice the tidal frequency (Symonds et al., 1995; Kraines et al., 1998) which drives associated fluctuations at other measurement sites.

An ensemble view of measured depth-averaged currents and main external parameters during the 2013 and 2015 experiments is shown in Figs. 4 and 5, respectively. The influence of tide on the depth-averaged currents is strong but appears to be site-dependent, as observed on the energy spectra in Fig. 3. The tide effect is clearly dominant for Isié and N'Digoro, less strong but still significant at Tenia and much smaller on the reef (Platier site). In this latter location, the overwhelming trend for lagoon-entering current is related to the nearly permanent wave breaking over the reef, as described by Chevalier et al. (2015). At the other sites, the tide effect is much more significant, inducing intense currents alternatively inward and outward during the emptying-filling cycles of the lagoon in response to tidal fluctuations. As expected, this tidal effect is more pronounced at the Isié reef opening which is the only direct connection to the open ocean in the considered zone. Day-averaged currents reveal that the mean general tendency is a positive (lagoon-entering) current at the Platier site and a negative (lagoon-leaving) current for the three other sites. A striking feature is that large wave events are associated with entering flux on the reef (Platier) and outward currents at each 

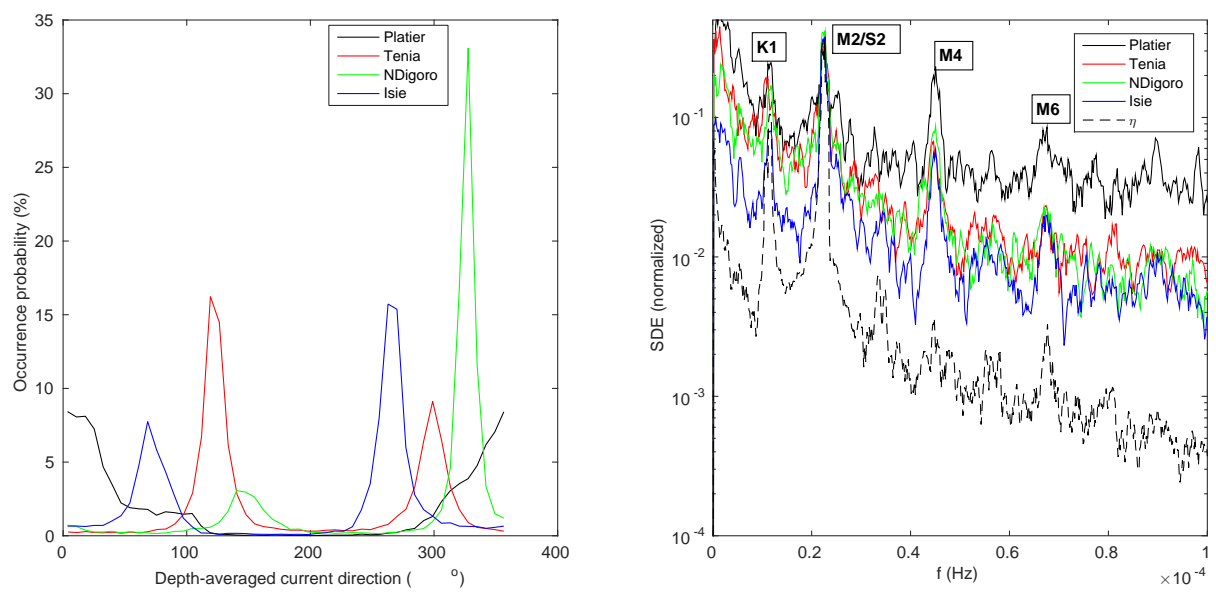

FIGURE 3: Depth-averaged current direction and normalized Spectral Density of Energy (dashed line is the SDE for the water level over the reef flat)

other site as shown by Chevalier et al. (2015) but this latter trend is not systematic as denoted for instance during the Feb. 8 or Mar. 14, 2015 wave events.

Further understanding on the lagoon dynamics is provided by the statistical inter-sites relationships depicted in Tab. 2 and in Fig. 6. Note that, for the sake of clarity, all relationships between sites are not plotted in Fig. 6 but a focus is made on the most significant ones in terms of lagoon circulation. In order to withdraw the effect of tide, the analysis of the dominant trends is performed on the day-averaged currents. The effect of external parameters, waves and wind, on the measured currents is discussed later on in sections 3.2 and 3.3. Further analysis will be carried throughout the text to finally characterize the circulation patterns in section 3.4 .

The following trends on links between sites can be deduced from Tab. 2 and Fig. 6.

- Strong connection is observed between the two northern sites N'Digoro and Isié. The day-averaged currents are generally negative (outward) and nearly linearly related (black circles in Fig. 6 A).

- The correlation is weaker between northern and southern passages (see $U_{\text {tenia }}^{\text {da }}$ and $U_{\text {ndigoro }}^{\text {da }}$ in Fig. 6 A). One notes that strong currents at Tenia can be either in- or outward while weak northern flow conditions are associated to outflow in Tenia.

- The Platier main component is fairly anti-correlated to the N'Digoro site. A similar link, not shown here, is observed with Isié.

- A strong connection is observed between $U_{\text {tenia }}^{\text {da }}$ and $V_{\text {platier }}^{\text {da }}$. However, slightly different slopes in the $U_{\text {tenia }}^{d a} / V_{\text {platier }}^{\text {da }}$ relationships are observed for positive and negative currents (see dash-dotted and dashed lines in Fig. 6, B). As discussed later on in section 3.4, this latter trend tends to indicate two distincts functionings of the southern part of the lagoon : south-eastward currents should be associated to converging water fluxes in the Tenia passage leading to a magnitude increase of $U_{\text {tenia }}^{d a}$ with respect to $V_{\text {platier }}^{\text {da }}$ while, on the opposite, periods of north-westward velocities correspond to more defined (channelized) current entering the lagoon through Tenia and flowing along the reef barrier allowing a better flux conservation between both sites.

- The linear correlation between day-averaged $U_{\text {tenia }}^{d a}$ and $V_{\text {platier }}^{d a}$ is very weak. However, Fig. 6, B, 

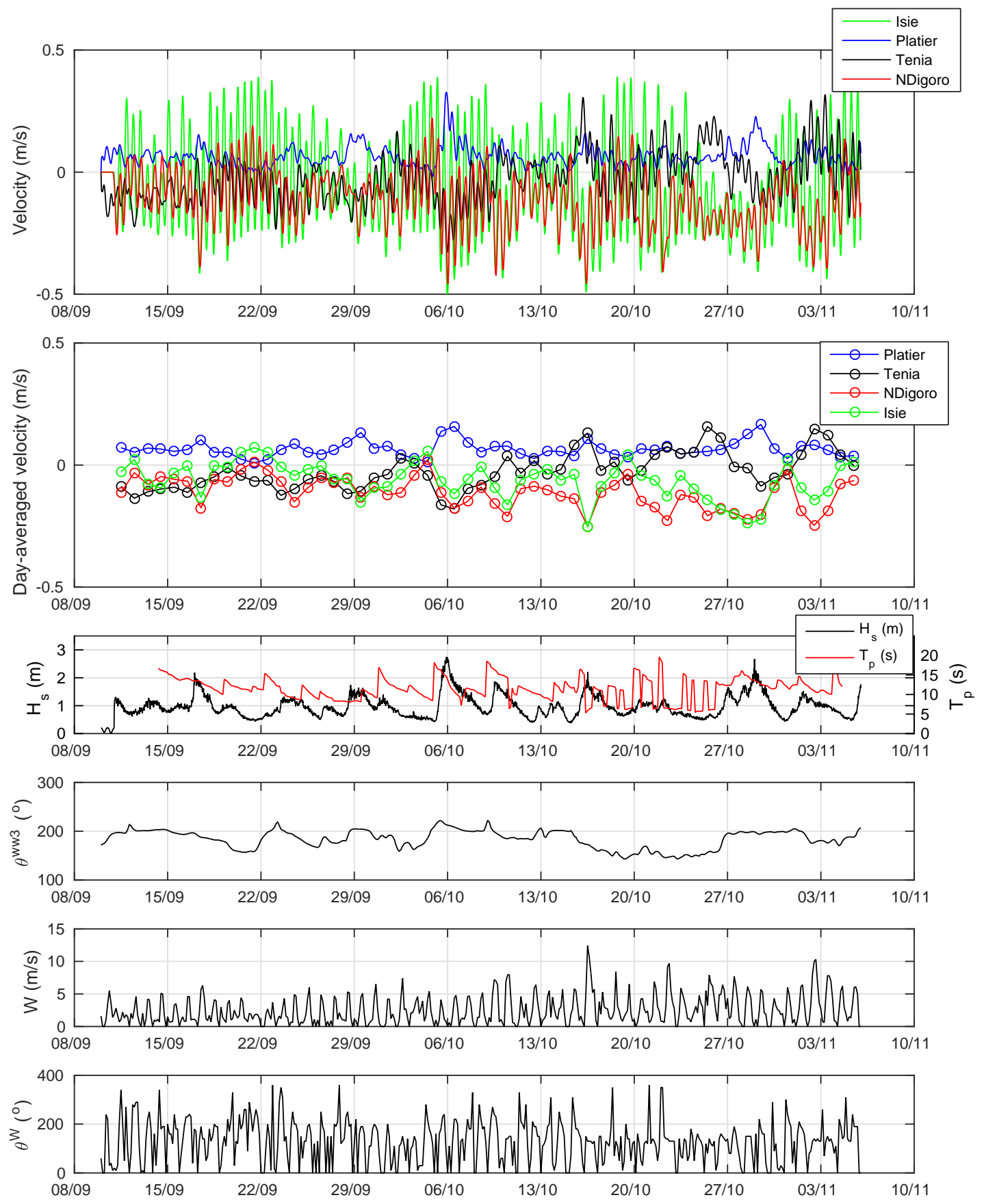

Figure 4: Data overview for the 2013 experiment. From top to bottom : depth-averaged currents, detided depth-averaged currents, significant wave height and peak period at the reef outer slope sensor, wave direction from WW3, wind intensity and direction. 

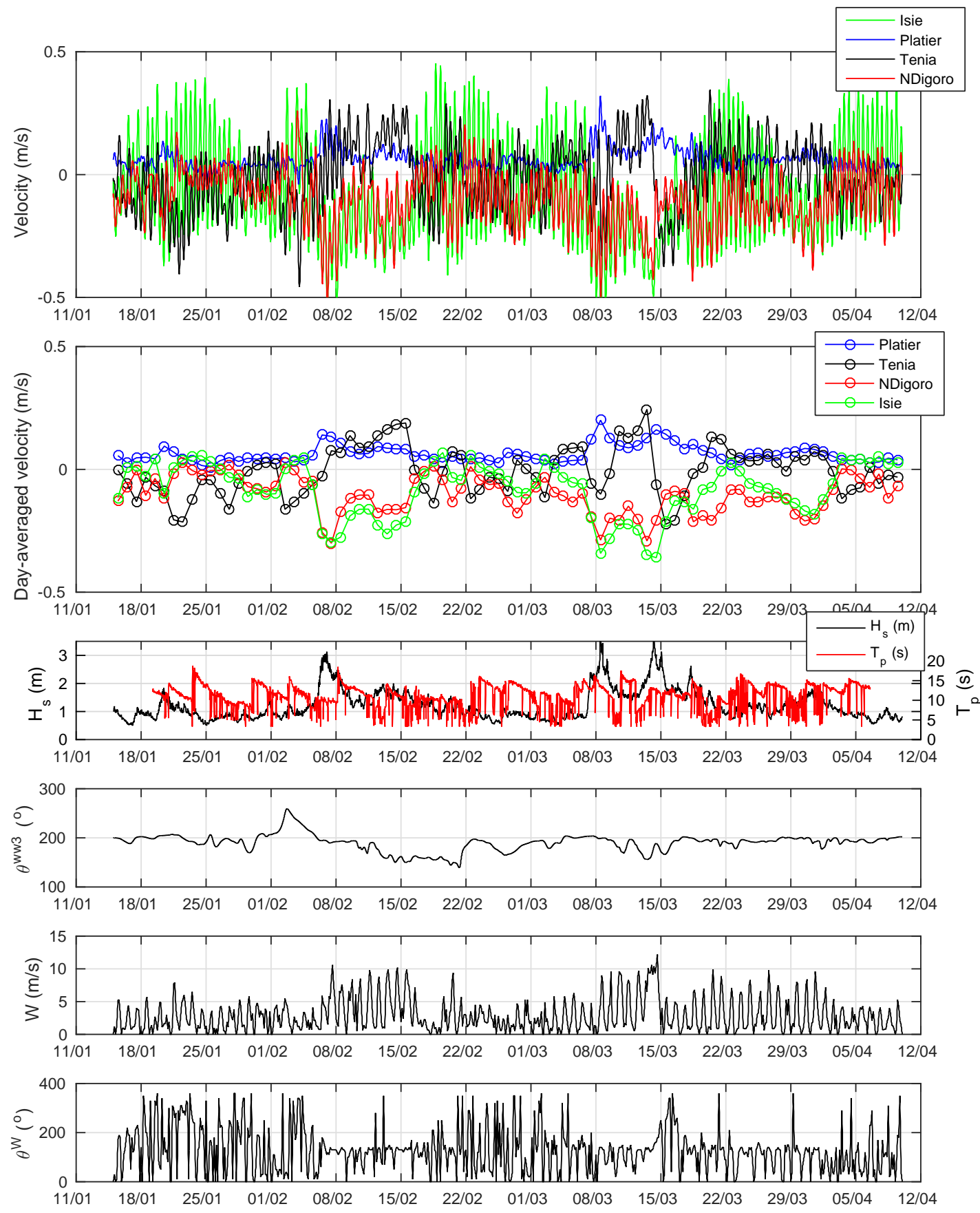

Figure 5: Data overview for the 2015 experiment. From top to bottom : depth-averaged currents, detided depth-averaged currents, significant wave height and peak period at the reef outer slope sensor, wave direction from WW3, wind intensity and direction. 


\begin{tabular}{|c|c|c|c|c|c|c|c|c|c|c|}
\hline & $U_{\text {isie }}$ & $U_{\text {ndigoro }}$ & $U_{\text {platier }}$ & $U_{\text {tenia }}$ & $V_{\text {platier }}$ & $U_{\text {isie }}^{\text {da }}$ & $U_{\text {ndigoro }}^{\text {da }}$ & $U_{\text {platier }}^{\text {da }}$ & $U_{\text {tania }}^{\text {da }}$ & $V_{\text {platier }}^{\text {da }}$ \\
\hline \hline$U_{\text {isie }}$ & - & 73.4 & -31.3 & 12.1 & -40.6 & - & - & - & - & - \\
$U_{\text {ndigoro }}$ & - & - & -38.3 & -14.6 & -41.4 & - & - & - & - & - \\
$U_{\text {platier }}$ & - & - & - & 6.3 & 9.7 & - & - & - & - & - \\
$U_{\text {tenia }}$ & - & - & - & - & 54.5 & - & - & - & - & - \\
$U_{\text {isie }}^{\text {da }}$ & - & - & - & - & - & - & 81.5 & -81.5 & -44.2 & -37.7 \\
$U_{\text {ndigoro }}^{\text {da }}$ & - & - & - & - & - & - & - & -71.3 & -56.1 & -49.1 \\
$U_{\text {platier }}^{\text {da }}$ & - & - & - & - & - & - & - & - & -1.3 & -0.3 \\
$U_{\text {tenia }}^{\text {da }}$ & - & - & - & - & - & - & - & - & - & 89.3 \\
$H_{s}$ & -33.5 & -41.9 & 77.6 & -4.3 & -4 & -77.5 & -66.5 & 94.5 & -4.6 & -6.9 \\
$T_{p}$ & -3.9 & -1.7 & 14.4 & -12.2 & -11 & -11.8 & -8.4 & 23.8 & -14.4 & -15.2 \\
$\theta^{\text {ww3 }}$ & 10.3 & 6.7 & 5.2 & -30.1 & -26.7 & 10.1 & 15.2 & 6.8 & -40.9 & -38.5 \\
$W$ & -14.1 & -15.9 & 7.9 & 20.4 & 8.9 & -63.7 & -58.2 & 40.3 & 60.1 & 59.9 \\
$\theta^{W}$ & 3.9 & 5.2 & -3.2 & -10.4 & -10.7 & 20.5 & 21.3 & -4.8 & -31.7 & -29.2 \\
\hline
\end{tabular}

TABLE 2: Correlation coefficients (in \%) quantifying the currents dependence to external forcings and the inter-relationships

shows that : (i) $U_{\text {platier }}^{\text {da }}$ is systematically positive, (ii) the strongest values of $U_{\text {platier }}^{\text {da }}$ are associated to negative $U_{\text {tenia }}^{d a}$ and, (iii), for moderate Platier currents, currents through Tenia passage can be either in- or outward.

Correlation coefficients for complete velocity signals presented in Tab. 2 are generally much lower than their day-averaged counterparts. This highlights in particular the role of phase shift during the tide propagation inside the lagoon : the tidal filling-emptying cycles are not in phase at each site, as described by Chevalier et al. (2015).

\subsection{Wave effect}

Table 2 shows that, as expected, the influence of waves and wind is greater on the day-averaged currents as the tidal-related components have been removed from the signal. The significant wave height $H_{s}$ is, apart from the tide, the dominant external parameter affecting the main current component at Isié, N'Digoro and Platier sites. The sign of correlation coefficients indicates that an increase of significant wave height promotes (negative) outward directed currents at Isié and N'Digoro sites and inward (positive) current over the reef at Platier. This is confirmed in Fig. 7A which shows a monotonic increase of the magnitude of $U_{\text {isie }}^{d a}$ and $U_{\text {platier }}^{d a}$ when increasing the incoming significant wave height. The overall tendency is that the increase of offshore wave energy induces stronger inward cross-reef fluxes generated by wave-breaking above the barrier. This water input all along the reef barrier is compensated by outward currents in each passage and reef opening, see (Chevalier et al., 2015) for a parameterization of wave-induced cross-reef fluxes. The response of the 

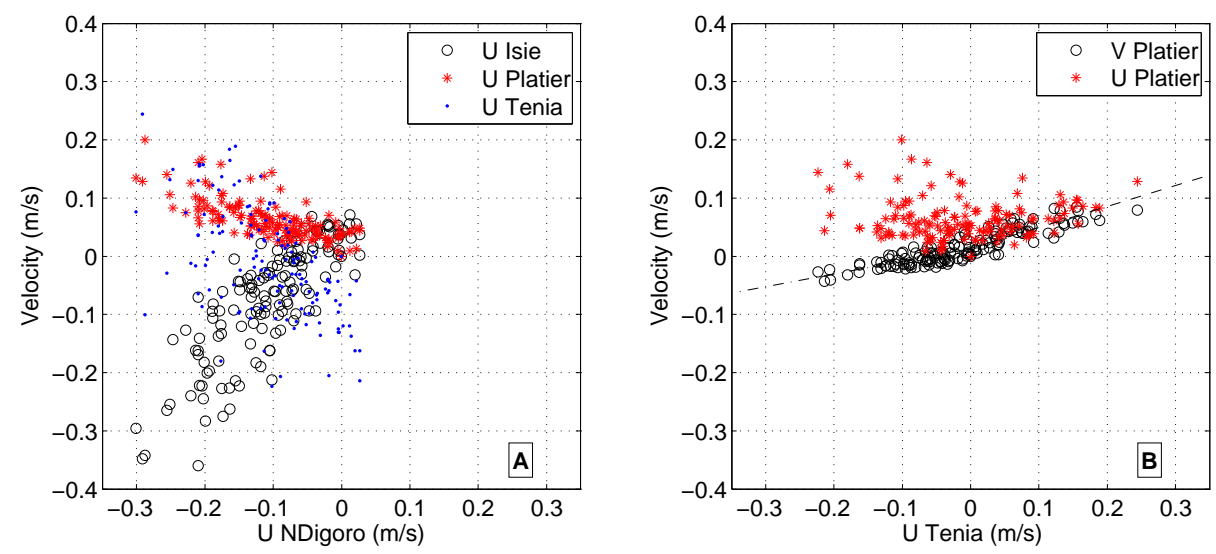

FiguRE 6: Inter-connections between day-averaged detided currents at selected sites. A : $U_{\text {isie }}^{\text {da }}$ (black circles), $U_{\text {platier }}^{\text {da }}$ (red stars) and $U_{\text {tenia }}^{\text {da }}$ (blue dots) vs $U_{\text {tenia }}^{\text {da }}$. B $: V_{\text {platier }}^{\text {da }}$ (black circles) and $U_{\text {platier }}^{\text {da }}$ (red stars) vs $U_{\text {tenia }}^{d a}$. Dash-dotted and dashed lines are linear regression for $V_{\text {platier }}^{\text {da }}$ vs $U_{\text {tenia }}^{\text {da }}$ for negative and positive values of $U_{\text {tenia }}^{\text {da }}$, respectively.

N'Digoro currents (not depicted here) is very close to the Isié one. However, this general circulation trend, already depicted in Chevalier et al. (2015), is not the sole circulation system in the lagoon. In particular, at Tenia (see blue dots in Fig. 7A), the day-averaged currents show no clear correlation with wave height and most of wave conditions are possibly associated to inward or outward currents.

The question arises now on the external conditions controlling the flushing or filling dynamics through the Tenia passage. While wave period does not show any noticeable statistical effect on depth-averaged currents, wave direction tends to anti-correlated with day-averaged $U_{\text {tenia }}^{\text {da }}$ and $V_{\text {platier }}^{\text {da }}$ with moderate correlation coefficients being -40.9 and $-38.5 \%$ respectively. Fig. $7 \mathrm{~B}$ depicts the corresponding relactionships. In spite of the measurement spread, one notes the overall trend that eastern wave direction tend to promote positive current in Tenia and along the reef at Platier while western swells induce outflow at Tenia.

\subsection{Wind effect}

The correlation coefficients on both complete and day-averaged currents are presented in Fig. 8. The statistical effect of wind on the day-averaged lagoon dynamics is noticeable. It is negatively correlated with the northern sites and positively correlated anywhere else : strong south-east winds promote a north-west bulk motion within the lagoon $\left(V_{\text {platier }}>0\right)$ and throughout the reef passages $\left(U_{\text {tenia }}>0\right.$ and $\left.U_{\text {ndigoro }}<0\right)$ and openings $\left(U_{\text {isie }}<0\right)$. In addition, additional computations have shown that the wind effect is quite weaker when using detided currents : correlation coefficients are -30.3, -23.8, 17.5, 28.2 and $25.3 \%$ for $U_{i s i e}^{d t}$, $U_{n d i g o r o}^{d t}, U_{\text {platier }}^{d t}, U_{\text {tenia }}^{d t}$ and $V_{\text {platier }}^{\text {da }}$, respectively. This trend is confirmed in Fig. 8 which depicts the wind correlation with detided and day-averaged transverse along-reef Platier current. The observed difference between subplots demonstrates the inertia of the lagoon waters with respect to the wind forcing. The poor correlations between wind and detided currents (or even more with instantaneous currents as presented in Tab. 2) show that the lagoon currents do not directly react to the thermal breeze cyclic rotations of the tradewinds but at a longer time scale which is better revealed by day-averaged current values. The negative detided currents observed in Fig. 8 (left) during stron winds conditions precisely correspond to the slow and delayed adjustement of the lagoon circulation to wind forcing. Fig. 8 also shows the presence of a threshold 

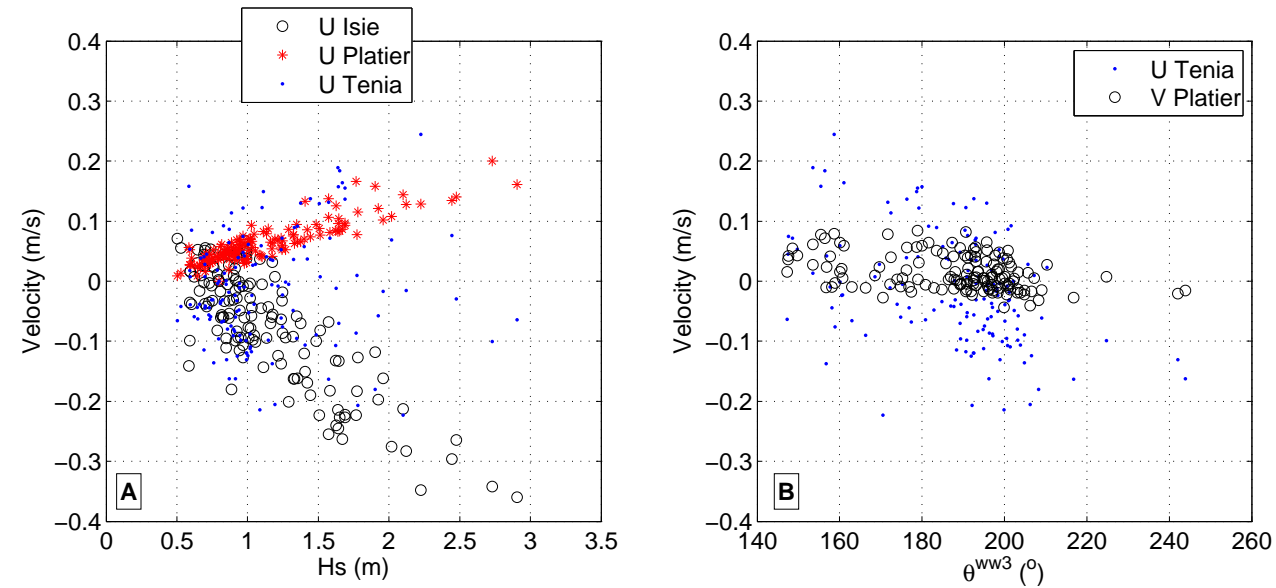

FiguRE 7: Influence of incoming wave features on the depth-averaged currents at selected sites. A : $U_{\text {isie }}^{d a}$ (black circles), $U_{\text {platier }}^{d a}$ (red stars) and $U_{\text {tenia }}^{\text {da }}$ (blue dots) vs $H_{s} . \mathrm{B}: U_{\text {tenia }}^{\text {da }}$ (blue dots) and $U_{\text {platier }}^{\text {da }}$ (black circles) vs $\theta^{w w 3}$.
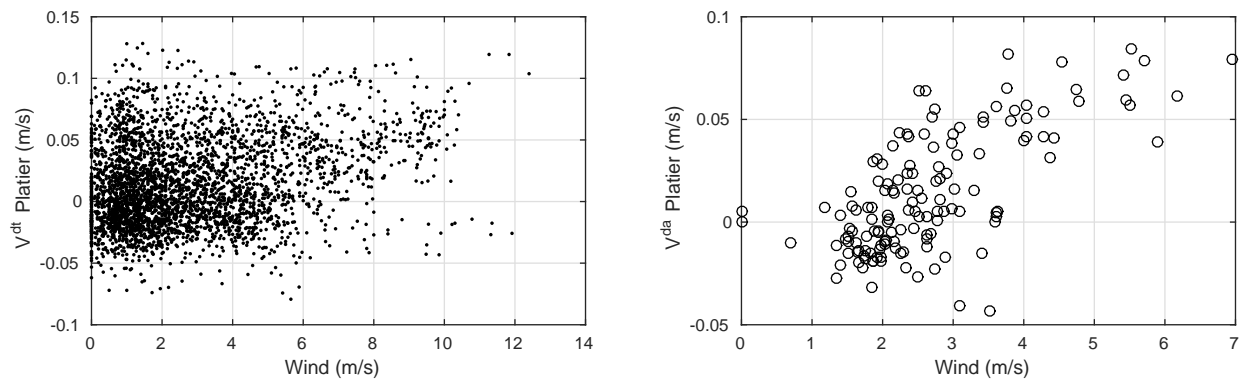

Figure 8: Influence of wind features on the depth-averaged along-reef current at Platier. Left : detided current. Right dayaveraged current. 

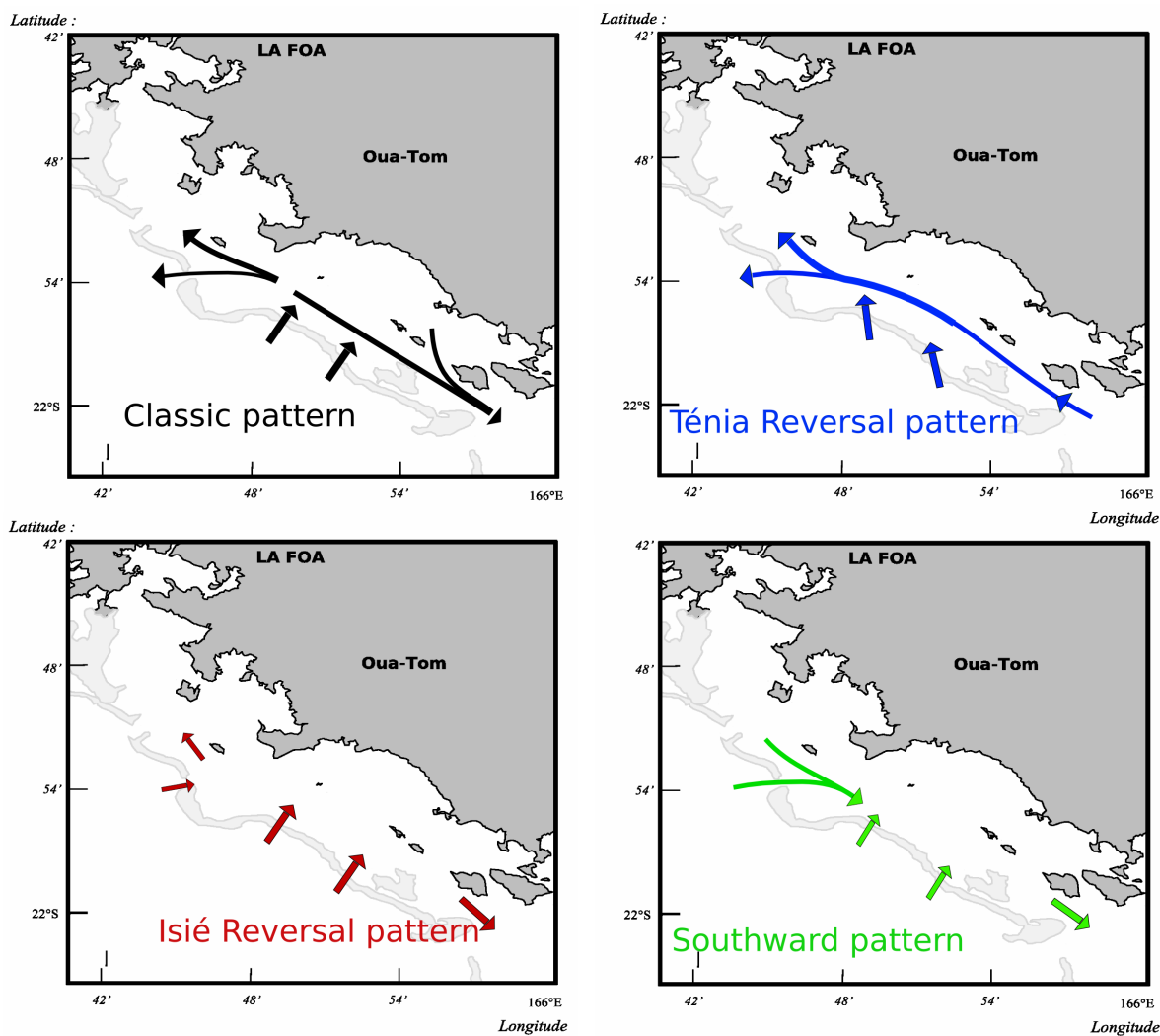

Figure 9: Schematic view of the circulation patterns in the Ouano lagoon.

in wind intensity around $3 \mathrm{~m} / \mathrm{s}$ from which $V_{\text {platier }}^{\text {da }}$ increases with wind intensity. For wind speed greater than $4 \mathrm{~m} / \mathrm{s}, V_{\text {platier }}^{\text {da }}$ is systematically positive. As observed in the wind rose in Fig. 2, such strong winds are coming from a narrow directional band between 125 and $140^{\circ}$ (in nautical convention). Similar tendencies with same wind intensity thresholds are observed at Tenia, Isié and N'Digoro sites.

\subsection{Circulation patterns}

The careful consideration of the presented data leads us to identify four dominant circulation patterns in the Ouano lagoon : the Classic Pattern (CP), the Tenia Reversal Pattern (TRP), the Isié Reversal Pattern (IRP) and the Southward Pattern (SP).

The hydrodynamical features (Fig. 9), occurence probabilities (Tab. 3) and onset conditions (Fig. 10) for each pattern are described below. The two dominant ones, i.e. CP and TRP, are described in more details through two four days selected events in Fig. 11. Furthermore, in order to understand their role in the lagoon flushing dynamics, one representative 24h-period has been selected for each pattern among the dataset : Sept. 212013 for SP, Sept. 222013 for IRP, Oct. 62013 for CP and Feb. 72015 for TRP. The measured depth-averaged currents are thus time-averaged over the corresponding $24 \mathrm{~h}$ period and displayed in Tab. 4. Estimation of related exchanged daily fluxes can be computed by using the cross-section areas of each site provided by the numerical bathymetry used by Chevalier et al. (2015). For the N'Digoro, Isié and Tenia sites, these cross-sections are about $2.09 .10^{4}, 1.15 .10^{4}$ and $2.85 .10^{4} \mathrm{~m}^{2}$, respectively. For Platier, as the 


\begin{tabular}{|c|c|c|c|c|}
\hline & $\mathrm{CP}^{d a}$ & $\mathrm{TRP}^{d a}$ & $\mathrm{IRP}^{d a}$ & $\mathrm{SP}^{d a}$ \\
\hline \hline Sept. - Nov. 2013 & 54.4 & 29.8 & 10.5 & 3.5 \\
\hline Jan. - Apr. 2015 & 27.9 & 40.7 & 19.8 & 5.8 \\
\hline Total & 38.5 & 36.4 & 16.1 & 4.9 \\
\hline
\end{tabular}

TABLE 3: Occurence probabilities (in \%) for the four selected patterns for day-averaged ( $d a$ ) currents.
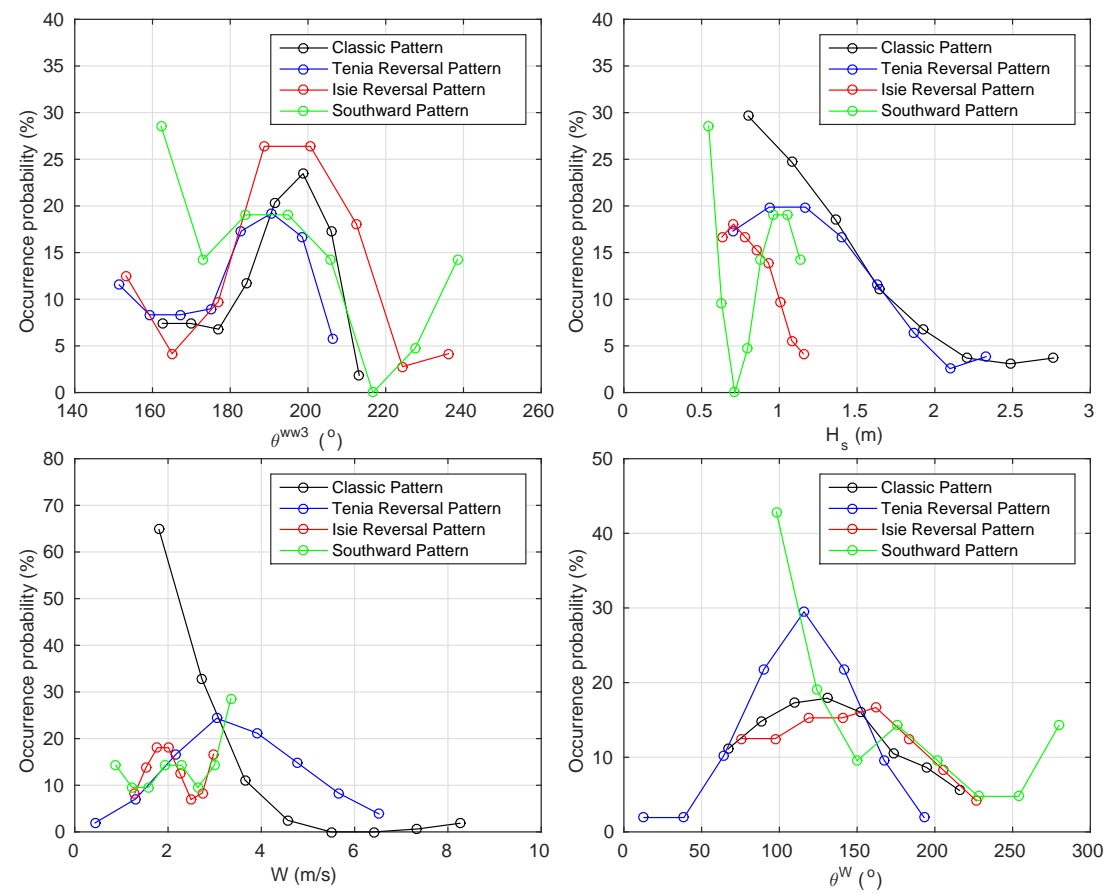

Figure 10: Classic and Tenia patterns

measurements are not performed on the top of the reef flat but on the inside slope of the barrier, the crosssectional area is estimated around the $-3.5 \mathrm{~m}$ isobath. It should be emphasized that the exchanged fluxes are subject to uncertainties due to the lack of precise bathymetric survey and better spatially-resolved current monitoring. They should thus be interpreted with caution and only used for inter-comparison purposes.

\section{The Classic pattern.}

The Classic pattern (CP) is characterized by :

- An inward flow above the reef barrier $\left(U_{\text {platier }}>0\right)$

- An outward flow in each passage and reef opening $\left(U_{\text {isie }}<0, U_{\text {ndigoro }}<0, U_{\text {tenia }}<0\right)$

The probability of occurence of CP is $53.6 \%$ (Tab. 3). This is thus the dominant circulation pattern in the lagoon. Figure 11 (left plots) shows a typical period of CP occuring from Oct. 5 to Oct. 8, 2013. One notes first that the setting up of the current pattern is related to the arrival of a large south-west swell event during the day of Oct. 5. The wave-breaking over the reef barrier induces an inward cross-reef flux at the Platier site. This flux, which progressively increases with increasing wave energy, promotes lagoon-leaving currents at other measurement sites. It is remarkable to note that even the flood tide at Tenia and N'Digoro 


\begin{tabular}{|c|c|c|c|c|}
\hline & CP & TRP & IRP & SP \\
\hline \hline$H_{s}(\mathrm{~m})$ & 1.9 & 2.4 & 0.6 & 0.5 \\
$T_{p}(\mathrm{~s})$ & 10.7 & 13.2 & 10.8 & 9.2 \\
$H_{s}^{W W 3}$ & 2.2 & 1.9 & 0.8 & 0.7 \\
$T_{p}^{W W 3}$ & 10.7 & 13.5 & 10.9 & 9.1 \\
$\theta^{W W 3}$ & 208 & 191 & 196 & 163 \\
$W(\mathrm{~m} / \mathrm{s})$ & 1.9 & 6 & 1.5 & 1.5 \\
$\theta^{W}$ & 120 & 126 & 107 & 205 \\
\hline$U_{\text {isie }}$ & -10.9 & -29.1 & 5.8 & 7.9 \\
$U_{\text {ndigoro }}$ & -16.8 & -29.7 & -2.2 & 1.3 \\
$U_{\text {platier }}$ & 15.5 & 13.2 & 2.4 & 0.9 \\
$U_{\text {tenia }}$ & -17.6 & 7.8 & -6.3 & -6.5 \\
\hline$F_{\text {isie }}$ & -1.2 & -3.3 & 0.7 & 0.9 \\
$F_{\text {ndigoro }}$ & -3.5 & -6.2 & -0.5 & 0.3 \\
$F_{\text {platier }}$ & 10.2 & 8.7 & 1.6 & 0.6 \\
$F_{\text {tenia }}$ & -5 & 2.2 & -1.8 & -1.9 \\
\hline
\end{tabular}

TABLE 4: Day-averaged currents $(U$ in $\mathrm{cm} / \mathrm{s})$ and corresponding estimated exchanged fluxes $\left(F\right.$ in $\left.10^{3} \mathrm{~m}^{3} . \mathrm{s}^{-1}\right)$ for four selected days corresponding to the four circulation patterns. Day-averaged values of wave and wind features are indicated for comparison. 

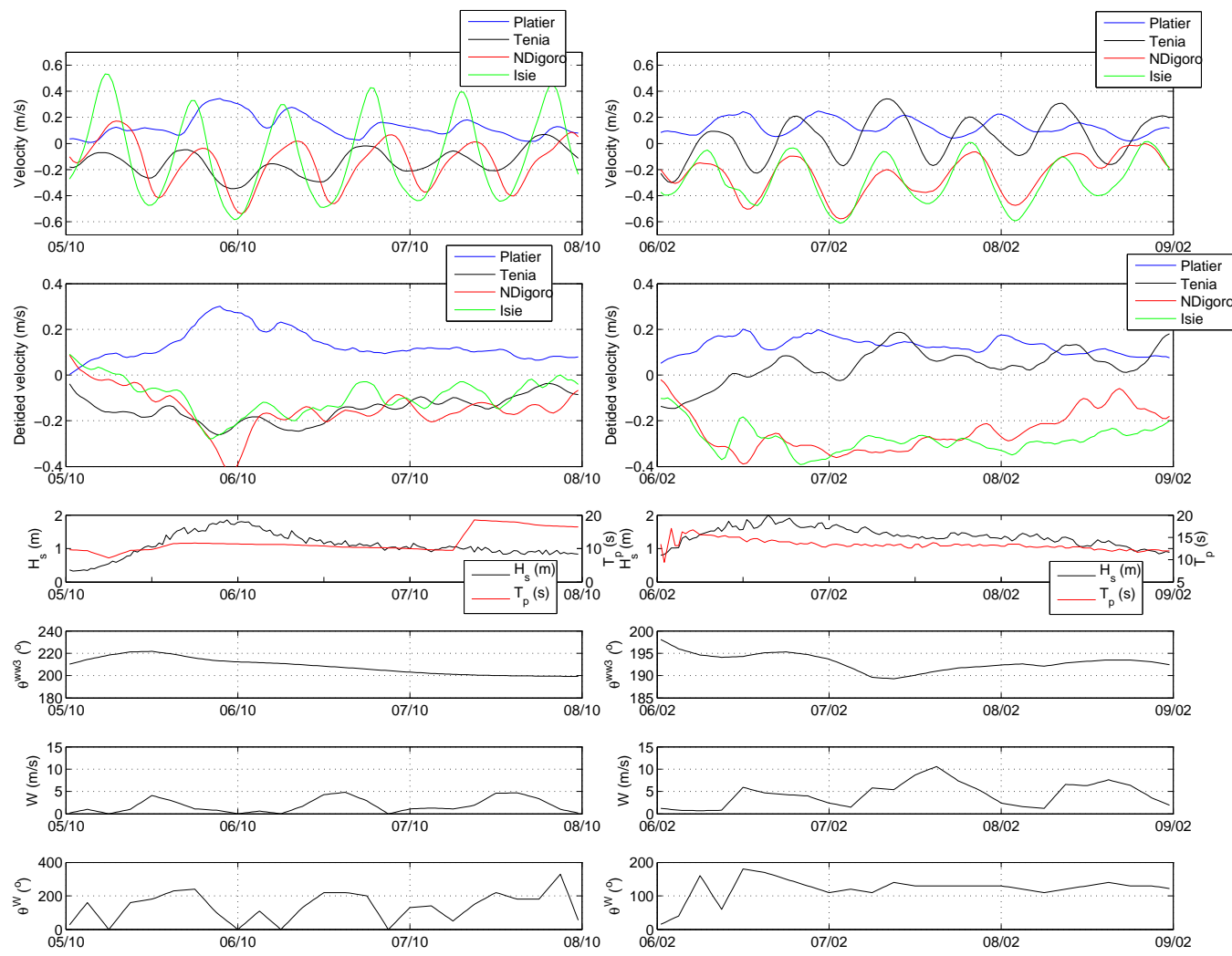

Figure 11: Examples of Classic Pattern and Tenia Reversal Pattern. From top to bottom : depth-averaged currents, depthaveraged detided currents, wave height and peak period, wave direction, wind intensity and direction.

sites is not able to compensate the outward flow. Currents are maximal aruond the swell apex, at high tide at Platier and during the ebb for other sites.

The onset conditions of CP for day-averaged currents are synthesized in Fig. 10. It is generally associated to large south-western swells and rather moderate winds. It appears that for the largest swells, CP is systematically observed, i.e. the lagoon-entering cross-reef flux is strong enough to dominate any other process. The breaking process over the reef is dependent of the ratio between wave height and water level above the reef (Hearn, 1999; Bonneton et al., 2007; Chevalier et al., 2015). When strong waves combinates with low tidal amplitude, the cross-reef flux induced by wave breaking can be so important that it pushes out water through each passages and reef opening (i.e. even at Isié) all along the tidal cycles, as depicted in Fig. 4 around Sept. 29 or Oct. 31, 2013. However, more data in large wave conditions $\left(H_{s}>3 m\right)$ should be gathered to substantiate this observation.

Day-averaged currents and estimated fluxes are given in Tab. 4 for the October, 6. One notes that, if depth-averaged velocities are of the same order of magnitude for each site, the input flux over the reef barrier is much more important than through passages and reef openings. Furthermore, the outward flux in Tenia is 2.5 times the along-reef flux in Platier, indicating the convergence process in the southern part of the lagoon.

\section{The Tenia reversal pattern.}

The Tenia reversal pattern (TRP) is characterized by : 
- An inward flow above the reef barrier $\left(U_{\text {platier }}>0\right)$

- An inward flow through Tenia passage $\left(U_{\text {tenia }}<0\right)$ generally associated to north-west current along the reef $\left(V_{\text {platier }}>0\right)$.

- An outward flow in the northern sites $\left(U_{\text {isie }}<0, U_{\text {ndigoro }}<0\right)$

The occurence probabilities of TRP for day-averaged currents are $28.6 \%$, respectively. A typical TRP is depicted in Fig. 11 (right plots) between Feb. 6 to 9, 2015. The main difference with CP is the observation of an inward flow at Tenia which magnitude oscillates with the tide but can remain in the same direction during several tidal cycles. The cross-reef flux measured at Platier site is still positive but a bit less intense during the swell peak than in CP presented above for similar type of wave height. This is attributed to the combined effects of, (i), a more southern wave direction which induces more westward (indeed WNW) flow above and along the reef and, (ii), a stronger south-east wind which drives lagoon waters toward north-west. However, in the considered case, the wind peak occurs after the establishment of the pattern. This latter appears thus to be mainly initiated by the swell arrival. TRP is related to a bulk north-west motion along the barrier (see the relationship between $U_{\text {tenia }}$ and $V_{\text {platier }}$ in Fig. 6, B), with water entering through Tenia from the neighbouring south-east lagoon and above the reef-barrier pushed by wave-breaking of south/south-east swell and leaving the lagoon through the northern openings.

Figure 10 shows that TRP is promoted by south to south-east swells and strong winds which are generally from south-east (Fig. 2). The comparison of estimated fluxes in Tab. 4 shows that, for similar range of incoming wave height, the exchanged fluxes through Isié and N'Digoro are much stronger in the TRP case. This emphasizes the major role played by the circulation patterns, driven by wave direction and wind magnitude, on the lagoon flushing dynamics and water renewal (Chevalier et al., 2014).

\section{The Isié reversal and Southward patterns.}

The Isié reversal and Southward patterns are discussed conjointly because they occur in quite similar conditions, i.e. small to moderate waves (typically $H_{s}<1.2 \mathrm{~m}$ ) and weak winds (typically $W<4 \mathrm{~m} / \mathrm{s}$ ) as depicted in Figs. 4 and 10. These patterns are not very stable and small waves periods are often characterized by alternating periods of IRP and SP.

Both Isié Reversal Pattern (IRP) and Southward Pattern (SP) are characterized by :

- An inward flow above the reef barrier $\left(U_{\text {platier }}>0\right)$

- An inward flow through Isié reef opening $\left(U_{\text {isie }}>0\right)$

- An outward flow in Tenia $\left(U_{\text {tenia }}<0\right)$

The only difference is that N'Digoro current is inward $\left(U_{\text {ndigoro }}<0\right)$ for SP and outward $\left(U_{n d i g o r o}>0\right)$ for IRP. The occurence probabilities for IRP and SP are respectively 12.5 and $3.6 \%$ in terms of day-averaged currents. The estimation of exchanged fluxes in Tab. 4 for selected $24 \mathrm{~h}$ period of IRP and SP indicates that these patterns, associated to low wave energy, are much less effective in the advection of water mass.

\subsection{Vertical structure}

The vertical structure of lagoon currents and its effect on the lagoon hydrodynamics, water renewal and biogeochemical processes have been little studied to date. Strong vertical variability has been highlighted in the Majuro Atoll numerical model (Kraines et al., 1999), with fast wind-driven surface layer (down to few meters) and much weaker or even return flows deeper in the water column possibly affected by baroclinic effects. The present data is purely hydrodynamical, i.e. the water properties such as salinity or temperature, 
which play a dominant role in stratification processes, are not documented by measurements. However, limiting our discussion to a purely currentological analysis, interesting observation can be performed on the vertical structure of flows through passages and reef openings.

As described in Section 2.1, the depth-averaged horizontal component of the vorticity $\frac{\partial U}{\partial z}$ is computed to provide a quantitative estimation of the vertical shear. Fig. 12 shows the relationship between depth-averaged vorticity and main component of currents for each site. Color levels in left and right columns indicate wind magnitude and wave height, respectively. Only one third of the dataset are depicted for the sake of clarity. These plots should be interpreted as follows :

— Zero vorticity : no vertical shear in the water column.

- Both positive vorticity and velocity : the current over the whole water column is entering into the lagoon, the surface layer moves faster than the bottom water.

- Both negative vorticity and velocity : the current over the whole water column is leaving the lagoon, the surface layer moves faster than the bottom water.

- Positive vorticity and negative velocity : the depth-averaged current leaves the lagoon, the bottom layer moves faster than the surface layer. In some cases, this latter can even flows in an opposite direction (i.e. being positive lagoon-entering) than the bottom layer.

- Negative vorticity and positive velocity : the depth-averaged current enters the lagoon, the bottom layer moves faster than the surface layer. In some cases, this latter can even flows in an opposite direction (i.e. being negative lagoon-leaving) than the bottom layer.

One notes first, for a substantial portion of the measured data, the importance of the vertical shear. For illustration, a vertical vorticity of $0.05 \mathrm{~s}^{-1}$ over a $10 \mathrm{~m}$ deep measurement water colum leads to a vertical variation of the velocity of $0.5 \mathrm{~m} / \mathrm{s}$. The presence of flow reversal within the water column, i.e. opposite directions for surface and bottom layers, is observed in 16, 28, 29 \% of the considered data for the Isié, Tenia and N'Digoro sites, respectively. It occurs generally during the tide reversal, when depth-averaged velocities are small.

The data distribution observed in Fig. 12 shows two overall tendencies : vertical shear generally increases with current velocity and vorticity is preferentially of the same sign as velocity, i.e. surface water moves faster than bottom one. The main exception to this trend is observed at Isié where inward current can show significant vorticity either positive or negative. In addition to this base functioning, the effects of wind and wave on the vertical shear are displayed by color labels in left and right columns, respectively. Strong winds (blowing from south-east) are generally associated to strong (negative) vertical shear associated with the outward currents at Isié and N'Digoro. This describes the expected effect of wind which enhances the north-west surface transport over the whole lagoon. At Tenia, the wind does not show a direct effect on the vertical shear and strong wind events are mainly associated to strong inward weakly sheared currents. One notes also that, at each site, large value of vorticity can be observed during calm wind periods. The wave effect is quite similar to that of the wind, although less marked. Strong wave events are generally related to outward sheared currents at Isié and N'Digoro whereas at Tenia no clear dependency is observed.

From the data presented in Fig. 12 and an overall analysis of the measured profiles, the vertical structure of the currents in passage and reef opening can be summarized as follows :

- During well-established currents and circulation patterns, the surface layers are generally moving faster than the bottom ones. 

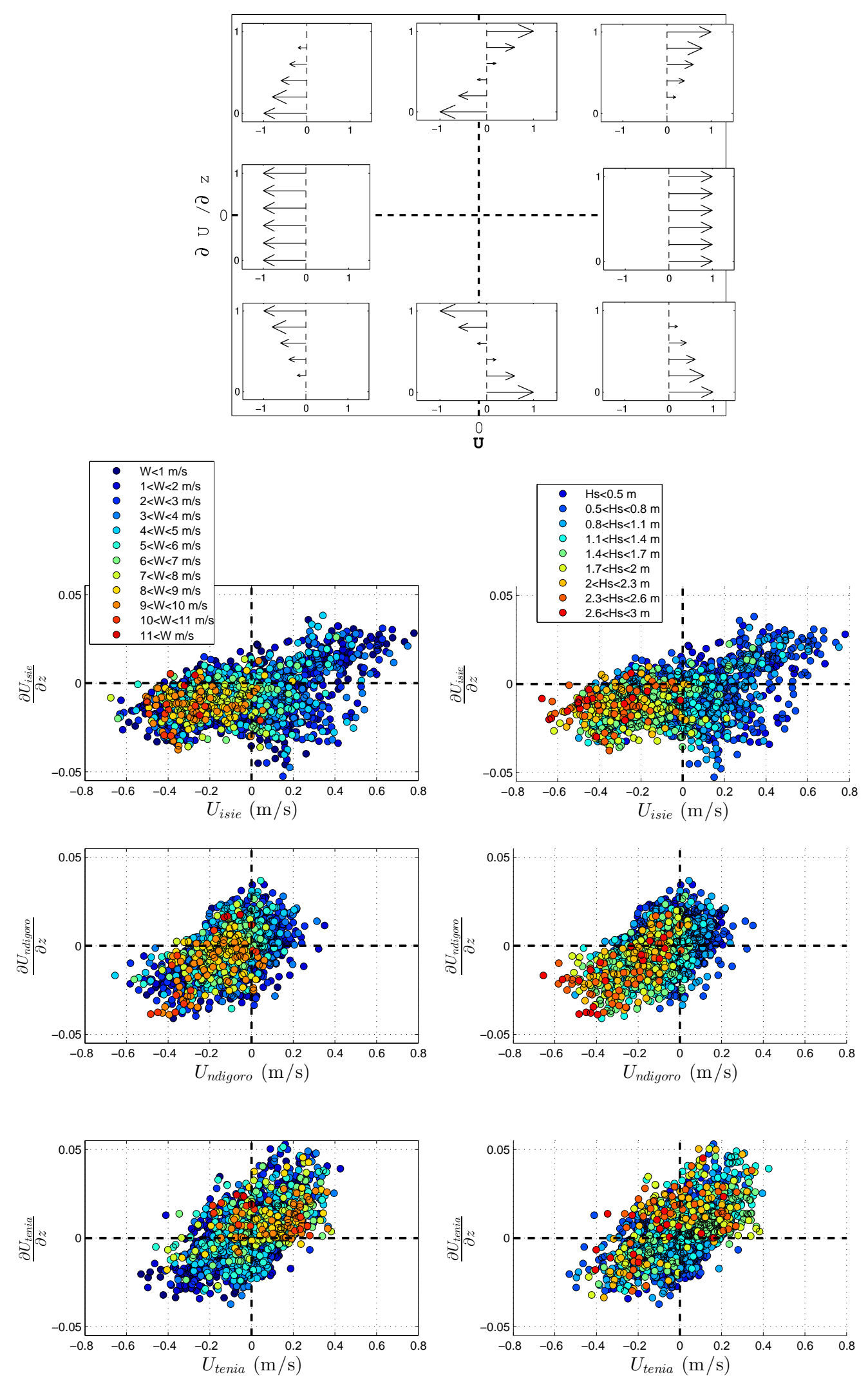

19

Figure 12: The top plot provides a scheme to help the data interpretation of the results in terms of vertical profiles, the $\mathrm{x}$ and y-axis being the depth-averaged current and the vorticity, respectively. Current vorticity vs intensity for Isié, N'Digoro and Tenia. Color labels provide information of the wind magnitude (in $\mathrm{m} / \mathrm{s}$ ) and wave height (in $\mathrm{m}$ ) for left and right plots, respectively. 
- In most cases, the vorticity is roughly constant in the water column (linear velocity profile)

- The wind, generally eastern, affects as expected the vertical shear by accelerating the surface layer when depth-averaged current is inward (e.g. during TRP events) or slowing down the surface layer of outward flows.

- Opposite signs of depth-averaged velocity and vorticity can be observed, i.e. bottom layers moving faster than surface ones, in particular (but not exclusively) during switchovers from TRP to CP.

Note that due to the time scales of the external forcings, in particular tide and thermal breeze, and the lagoon depth (typically about 10m) and topographical constraints, the Ekman's effect on the current vertical structure is expected to be weak, in particular in comparison to the direct action of wind stress at the surface. Additional data processing will be carried out to further explore this issue.

\section{Discussion}

\section{A generic functionning for channel lagoons?}

The hydrodynamical field measurements presented here provide a valuable dataset for the understanding of lagon circulation and a relevant benchmark for numerical modeling. It shows the importance of the combined effects of tides, waves and wind which must all be taken into account in numerical models to provide a proper characterization of water renewal dynamics. The main processes observed in the Ouano lagoon should be representative of similar types of reef-lagoon systems that we defined as channel lagoons. The distinctive features of such lagoons are :

- a well-defined barrier reef

- a typical lagoon depth (5-50m) much greater than the depth over the reef top (typically outcropping during low spring tides),

- a reef-parallel dimension (length) of the lagoon much greater than the reef-normal dimension (width), i.e. with an aspect ratio of the order of $2-10$,

- longitudinal bathymetric gradients smaller than their transverse counterparts,

- one or several passages toward open ocean or adjacent lagoons.

Typical channel lagoons can be found for instance in the Pacific Ocean :

- New Caledonia, west and east coasts;

- French Polynesia, east coast of Moorea, Huahiné, Raiatea-Tahaa, Tahiti Iti and Nui ;

- Japan, south-west Okinawa (Bibi beach);

- Fiji, Viti Levu, Nairai and Kandavu;

- Samoa, Naunonga (Vanikoro), Utupoa;

or in the Indian Ocean in Madagascar (Tulear) or in Maurice (north Mahebourg). Various tides, waves and wind conditions can be encountered at each site but the renewal time of lagoon waters typically ranges from few days to few weeks. Such time scales are, on one hand, sufficient to allow the setting up of a wide range of bio-geochemical processes (the lagoon can produce its "own" waters) and, on the other hand, short enough to be permanently affected by the fluctuations of ocean and atmospheric forcings : swell events, storms, spring/neap tide cycles, winds, etc. The present experiments demonstrates that, in addition to the tidal cycles, the wave and wind plays an important role in the lagoon circulation. The wave-breaking cross-reef fluxes are generally able, indepently to the tide, to renew the lagoon water in few days to few weeks. This wave 
effect, which is enhanced as the length to width ratio of the lagoon increases, can drive different current patterns depending on the swell direction and magnitude, possibly blocking or reversing the tidal fluxes through passages and reef openings. The wind stress affects the vertical flow structure and also participate to the reverse of the whole lagoon circulation when strongly blowing over a sufficient period of time (typically few days). Depending on the lagoon geometry, the difference between patterns, which can alternatively drive water from/into the open ocean or from/into the neighbouring lagoons in variable proportions, can lead to important consequences in terms of water properties and biogeochemical processes.

\section{Seasonal variability}

The comparison between 2013 and 2015 experiments shows significant difference in occurence probability for CP and TRP (see Tab. 3), in relation with different wave and wind climates. The question arises on the presence of a seasonal variation in the lagoon dynamics, with a dominant CP tendency during the austral spring (August-November) and a dominant TRP tendency during the austral autumn (February-April). This hypothesis is first supported by the preliminary experiment performed in 2011 from mid-july to october which shows an dominant outward day-averaged flow at Ténia (about $67 \%$ of time), i.e. corresponding to CP trend. Numerical wave statistics on the 1994-2012 period provided by WW3/IOWAGA data are depicted in Fig. 13. The whole wave partitions are explored to compute the occurence frequency of swells components $\left(H_{s}>1 \mathrm{~m}\right)$ coming from eastern $\left(\theta<200^{\circ}\right.$, black circles in Fig 13) and western $\left(\theta>200^{\circ}\right.$, red circles in Fig 13) sectors. A clear seasonal variation is observed : western swells are clearly dominant between may and november while eastern swells are more present during the austral summer. In addition Meteo France wind data at Tontouta airport from 2006 to 2015 are processed to depict the occurence probability for strong eastern winds $(W>5 \mathrm{~m} / \mathrm{s})$ in green circles in Fig. 13. A statistical trend is observed, with more frequent strong wind events between September and March than during the rest of the year. According to the previous analysis, it is likely that the difference in lagoon circulation observed between 2013 and 2015 (and 2011) experiments are indeed representative of a cyclic seasonal variation. Even if the available hydrodynamical data does not cover the full annual variations, one can expect a dominance of CP from may to september when swells are predominantly from the west and winds are rather calm and, conversely, a dominant TRP during the austral summer between December to April when strong winds and eastern swells are more frequent. The renewal of lagoon waters should then be mainly controlled by inflow of open ocean waters during the austral winter and inflow from south-eastern neighbouring lagoon through Tenia passage the rest of the year.

\section{Impact of the Pam tropical cyclone}

Extreme meteorological events are able to strongly impact the flow pattern in reef-lagoon systems. This is illustrated in the present dataset by the passage of the severe tropical cyclone Pam recorded during the 2015 experiments. The Pam tropical cyclone, which was one of the worst natural disasters in the history of Vanuatu, formed on March 6, 2015 east of the Solomon Islands and moved southward when intensifying to reach the Vanuatu islands on March 13 and finally decay on March 15 northeast of New Zealand. It is responsible for the strong south to south-east winds (Tontouta airport measurements) and large waves (WW3 simulations) observed in between March 10 and 15. Such cyclone-related forcings induces the most intense TRP conditions observed within the present dataset, with permanent strong inflow through Tenia passage 


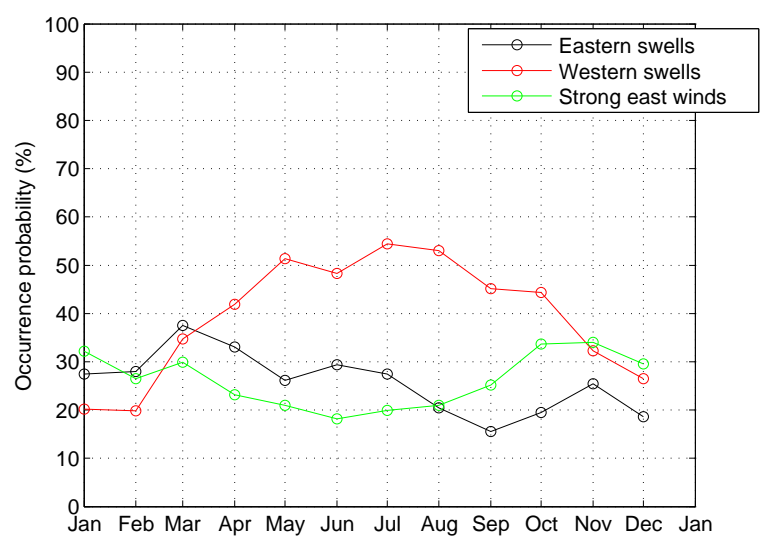

Figure 13: Occurence probability of swells from eastern $(\theta<200$, black circles in Fig 13) and western $(\theta>200$, red circles in Fig 13) sectors from 1994-2012 IOWAGA/WW3 numerical datasets and strong eastern winds $(W>5 \mathrm{~m} / \mathrm{s})$.

and outflow through the northern sites over more than 4 days which totally overcome the tidal dynamics (see Fig. 5). The clear regime shift from TRP to CP on March 14/15, while wave height and wind intensity remain strong, should probably be attributed to the slight shift in wind and waves directions. The proper validation of such an hypothesis would have require direct measurements of wave direction at the system entry, which are not available with the present dataset. However, this observation tends to highlight the increased sensitivity of the circulation system to the forcings direction during severe and extreme conditions.

\section{Biogeochemical issues}

The existence of well defined circulation patterns in the reef-lagoon system is of primary importance to analyse and predict the biological productivity and its evolution (Cuif et al., 2014). During CP conditions, the lagoon is mainly fueled by across-barrier water inputs. During the reef barrier crossing, coral organisms and plankton-eating fishes tend, through ingestion and metabolism, to modify the nutrient composition (uptake and regeneration), to deplete food content of the incoming waters by grazing and predation (bacterio-, phyto- and zooplankton content) (Houlbreque et al., 2006; Hamner and Hamner, 2000; Cuet et al., 2011) and to increase the release of non living particles (mucus) by corals (Cuet et al., 2011) . Furthermore, from the exchanged volumes estimated hereinbefore, one can expect that $\mathrm{CP}$ would be less efficient in terms of water renewal than TRP for which water are entering the lagon both through the Tenia passage and above the reef barrier. Longer residence times for CP may be associated with an increase of the phytoplanktonic productivity of the lagoon (Delesalle and Sournia, 1992; Andréfouët et al., 2001), which can compete with cross-reef transformation processes. TRP is expected to foster the inflow from neighbouring south-eastern lagoons through Tenia passage rather than open ocean waters. Visual observations notably revealed the arrival of water loaded with appendicularians and jellyfishes during TRP.

Current shearings generated by thermal and salinity fronts have been observed to induce strong plankton aggregation in the lagoon context (Gomez-Gutierrez et al., 2007). The present study demonstrates the presence of significant vertical shear induced by the wind forcing alone. The effect of such vertical shearing of the currents may significantly affect the plankton migration. For instance, in the passages and reef openings, a strongly sheared current with inflow at the surface and outflow near the bed (as revealed by the present 
measurements) will play a dramatically different role depending on whether it occurs during day (zooplankton lying near the bed) and during night (zooplankton close to the surface).

All of these open questions should drive further ambitious research efforts. In particular, field campaigns must now be designed to measure simultaneously both hydrodynamical and biogeochemical properties of the reef-lagoon systems in order to gain a comprehensive understanding of these coupled processes.

\section{Conclusion}

From two field campaigns carried out in the Ouano lagoon, west New Caledonia, we have identified the main drivers of a typical channel lagoon. The selected lagoon - barrier reef system is exposed to south pacific swells, meso-tides and trade winds modulated by the thermal breeze. A network of current profilers has been deployed during two successive three-months field campaign in order to monitor the current within reef passages and openings in a wide range of hydrodynamical and meteorological conditions. Pressure sensors are used to monitor the incoming wave features on the outside reef slope.

The first driver of the lagoon hydrodynamics is the tide which induces periodic filling/flushing cycles of the lagoon well identified on both free surface and currents measurements. In addition, a modulation of currents at twice the tidal frequency has been observed, in response to the modulation of cross-reef flow (Symonds et al., 1995; Kraines et al., 1998). The analysis of day-averaged depth-averaged currents allows to identify both the inter-connections between measurement sites and their dependence to the external forcings. The effect of wave is straightforward : as soon as waves break on the reef top, an entering flow is observed above the reef barrier whatever the tide, increasing with wave energy. For the strongest swells, the cross-reef water input is such as depth-averaged currents are permanently outward at each other site, even during rising tide. For all other conditions, the current dynamics in reef openings and passages is mainly controlled by wave direction and wind magnitude. The comparison between detided and day-averaged currents highlights the slow day-scale adjustement of the lagoon circulation to the wind stress. Four typical circulations have been characterized, with the two first controlling the lagoon dynamics more than $70 \%$ of time :

- The Classic Pattern corresponds to a day-averaged outflow at each passage and opening, occuring during moderate wind and south-west wave conditions.

- The Tenia Reversal Pattern is defined by an input day-averaged flow at the southern opening driving an overall bulk water motion toward north-west. This pattern is forced by strong winds and/or swells coming from south-east

- The Isié and Southwards Patterns are observed in calm conditions. They are characterized by a reversal of the day-averaged current in the northern opening of the lagoon. They are much less stable than the two previous patterns which last for several days as long as the wave or wind forcings maintain.

Following the fluctuations of the meteorological forcings, the lagoon is expected to show a seasonal functioning, with dominant inputs from open ocean waters and from neighbouring eastern lagoons during austral summer and winter, respectively. Moreover, the sensitivity of the lagoon circulation to forcings direction is expected to increase during severe and extreme wave and wind conditions encountered during tropical storms or cyclones.

The analysis of the vertical structure of the current in lagoon passages shows the regular presence of a significant nearly linear vertical shear in the water column. This shear often appears during strong wind events but are also observed in calm conditions. The main tendency is that surface layer are faster than 
bottom ones, either for in- or out-flows. Period of reversal between patterns are generally associated to complex vertical structure of the current with opposite flows in the upper and lower parts of the water column.

\section{Acknowledgements}

This study was sponsored by the Action Sud MIO/IRD (A.S. OLZO and A.S. CROSS-REEF) and the ANR MORHOC'H (Grant No. ANR-13-ASTR-0007). The GLADYS group (www.gladys-littoral.org) supported the experimentation. We are grateful to all the contributors involved in this experiment. The authors are particularly indebted to David Varillon, Eric Folcher and Betrand Bourgeois whose efforts were essential to the deployment. A special thanks is extended to Jerôme Aucan for giving immediate and unconditional access to his data. 
Andréfouët, S., Pages, J., Tartinville, B., 2001. Water renewal time for classification of atoll lagoons in the tuamotu archipelago (french polynesia). Coral reefs 20 (4), 399-408.

Angwenyi, C. M., Rydberg, L., 2005. Wave-driven circulation across the coral reef at bamburi lagoon, kenya. Estuarine, Coastal and Shelf Science 63 (3), 447-454.

Atkinson, M., Smith, S., Stroup, E., 1981. Circulation in enewetak atoll lagoon. Limnol Oceanogr 26 (6), 1074-1083.

Bonneton, P., Lefebvre, J.-P., Bretel, P., Ouillon, S., Douillet, P., 2007. Tidal modulation of wave-setup and wave-induced currents on the aboré coral reef, new caledonia. J. Coast. Res 50, 762-766.

Carassou, L., Le Borgne, R., Rolland, E., Ponton, D., 2010. Spatial and temporal distribution of zooplankton related to the environmental conditions in the coral reef lagoon of new caledonia, southwest pacific. Marine pollution bulletin 61 (7), 367-374.

Chevalier, C., Devenon, J.-L., Rougier, G., Blanchot, J., 2014. Hydrodynamics of the toliara reef lagoon (madagascar) : Example of a lagoon influenced by both waves and tide. Journal of Coastal Research.

Chevalier, C., Sous, D., Devenon, J.-L., Pagano, M., Rougier, G., Blanchot, J., 2015. Impact of cross-reef water fluxes on lagoon dynamics : a simple parameterization for coral lagoon circulation model, with application to the ouano lagoon, new caledonia. Ocean Dynamics 65 (11), 1509-1534.

Cuet, P., Atkinson, M., Blanchot, J., Casareto, B., Cordier, E., Falter, J., Frouin, P., Fujimura, H., Pierret, C., Susuki, Y., et al., 2011. Cnp budgets of a coral-dominated fringing reef at la réunion, france : coupling of oceanic phosphate and groundwater nitrate. Coral Reefs 30 (1), 45-55.

Cuif, M., Kaplan, D. M., Lefèvre, J., Faure, V. M., Caillaud, M., Verley, P., Vigliola, L., Lett, C., 2014. Wind-induced variability in larval retention in a coral reef system : A biophysical modelling study in the south-west lagoon of new caledonia. Progress in Oceanography 122, 105-115.

Delesalle, B., Sournia, A., 1992. Residence time of water and phytoplankton biomass in coral reef lagoons. Continental Shelf Research 12 (7), 939-949.

Delhez, E. J., Campin, J.-M., Hirst, A. C., Deleersnijder, E., 1999. Toward a general theory of the age in ocean modelling. Ocean Modelling 1 (1), 17-27.

Delhez, É. J., de Brye, B., de Brauwere, A., Deleersnijder, É., 2014. Residence time vs influence time. Journal of Marine Systems 132, 185-195.

Fernando, H., McCulley, J., Mendis, S., Perera, K., 2005. Coral poaching worsens tsunami destruction in sri lanka. Eos, Transactions American Geophysical Union 86 (33), 301-304.

Gomez-Gutierrez, J., Martínez-Gómez, S., Robinson, C. J., 2007. Influence of thermo-haline fronts forced by tides on near-surface zooplankton aggregation and community structure in bahía magdalena, mexico. Marine Ecology Progress Series 346, 109-125.

Gourlay, M., 1996a. Wave set-up on coral reefs. 1. set-up and wave-generated flow on an idealised two dimensional horizontal reef. Coastal Engineering 27 (3), 161-193. 
Gourlay, M., 1996b. Wave set-up on coral reefs. 2. set-up on reefs with various profiles. Coastal Engineering 28 (1), 17-55.

Gourlay, M. R., Colleter, G., 2005. Wave-generated flow on coral reefs - an analysis for two-dimensional horizontal reef-tops with steep faces. Coastal Engineering 52 (4), 353-387.

GRENZ, C., Le Borgne, R., Torreton, J.-P., FICHEZ, R., 2013. New caledonia lagoon : a threatened paradise under anthropogenic pressure? Lagoons : Habitat and Species, Human Impacts and Ecological Effects, $\mathrm{xx}-\mathrm{xx}$.

Hamner, W. M., Hamner, P. P., 2000. Behavior of antarctic krill (euphausia superba) : schooling, foraging, and antipredatory behavior. Canadian Journal of Fisheries and Aquatic Sciences 57 (S3), 192-202.

Hardy, T. A., Young, I. R., 1996. Field study of wave attenuation on an offshore coral reef. Journal of Geophysical Research : Oceans (1978-2012) 101 (C6), 14311-14326.

Hearn, C., Parker, I., 1988. Hydrodynamic processes on the ningaloo coral reef, western australia. In : Proceedings of the Sixth International Coral Reef Symposium. Vol. 2. pp. 497-502.

Hearn, C. J., 1999. Wave-breaking hydrodynamics within coral reef systems and the effect of changing relative sea level. Journal of Geophysical Research : Oceans (1978-2012) 104 (C12), 30007-30019.

Hench, J. L., Leichter, J. J., Monismith, S. G., 2008. Episodic circulation and exchange in a wave-driven coral reef and lagoon system. Limnology and Oceanography 53 (6), 2681.

Hoeke, R. K., Storlazzi, C. D., Ridd, P. V., 2013. Drivers of circulation in a fringing coral reef embayment : a wave-flow coupled numerical modeling study of hanalei bay, hawaii. Continental Shelf Research 58, 79-95.

Houlbreque, F., Delesalle, B., Blanchot, J., Montel, Y., Ferrier-Pagès, C., et al., 2006. Picoplankton removal by the coral reef community of la prévoyante, mayotte island. Aquatic microbial ecology 44, 59-70.

Kench, P., McLean, R., 2004. Hydrodynamics and sediment flux of hoa in an indian ocean atoll. Earth Surface Processes and Landforms 29 (8), 933-953.

Kraines, S., Yanagi, T., Isobe, M., Komiyama, H., 1998. Wind-wave driven circulation on the coral reef at bora bay, miyako island. Coral Reefs 17 (2), 133-143.

Kraines, S. B., Suzuki, A., Yanagi, T., Isobe, M., Guo, X., Komiyama, H., 1999. Rapid water exchange between the lagoon and the open ocean at majuro atoll due to wind, waves, and tide. Journal of Geophysical Research : Oceans (1978-2012) 104 (C7), 15635-15653.

Lowe, R. J., Falter, J. L., Bandet, M. D., Pawlak, G., Atkinson, M. J., Monismith, S. G., Koseff, J. R., 2005. Spectral wave dissipation over a barrier reef. Journal of Geophysical Research : Oceans (1978-2012) 110 (C4).

Lowe, R. J., Falter, J. L., Monismith, S. G., Atkinson, M. J., 2009. Wave-driven circulation of a coastal reef-lagoon system. Journal of Physical Oceanography 39 (4), 873-893. 
Lugo-Fernandez, A., Roberts, H., Wiseman Jr, W., 1998. Tide effects on wave attenuation and wave set-up on a caribbean coral reef. Estuarine, Coastal and Shelf Science 47 (4), 385-393.

Massel, S., Gourlay, M., 2000. On the modelling of wave breaking and set-up on coral reefs. Coastal Engineering 39 (1), 1-27.

Masselink, G., 1998. Field investigation of wave propagation over a bar and the consequent generation of secondary waves. Coastal Engineering 33 (1), 1-9.

Monismith, S. G., 2007. Hydrodynamics of coral reefs. Annu. Rev. Fluid Mech. 39, 37-55.

Monsen, N. E., Cloern, J. E., Lucas, L. V., Monismith, S. G., 2002. A comment on the use of flushing time, residence time, and age as transport time scales. Limnology and Oceanography 47 (5), 1545-1553.

Pomeroy, A., Lowe, R., Symonds, G., Van Dongeren, A., Moore, C., 2012. The dynamics of infragravity wave transformation over a fringing reef. Journal of Geophysical Research : Oceans (1978-2012) 117 (C11).

Roberts, H. H., Murray, S. P., Suhayda, J. N., 1975. Physical processes in fringing reef system. Journal of Marine Research 33 (2), 233-260.

Roberts, H. H., Suhayda, J. N., 1983. Wave-current interactions on a shallow reef (nicaragua, central america). Coral Reefs 1 (4), 209-214.

Symonds, G., Black, K. P., Young, I. R., 1995. Wave-driven flow over shallow reefs. Journal of Geophysical Research : Oceans (1978-2012) 100 (C2), 2639-2648.

Szmant, A. M., 2002. Nutrient enrichment on coral reefs : is it a major cause of coral reef decline? Estuaries 25 (4), 743-766.

Taebi, S., Lowe, R. J., Pattiaratchi, C. B., Ivey, G. N., Symonds, G., Brinkman, R., 2011. Nearshore circulation in a tropical fringing reef system. Journal of Geophysical Research : Oceans (1978-2012) 116 (C2).

Tartinville, B., Rancher, J., 2000. Wave-induced flow over mururoa atoll reef. Journal of Coastal Research, $776-781$.

Van Dongeren, A., Lowe, R., Pomeroy, A., Trang, D. M., Roelvink, D., Symonds, G., Ranasinghe, R., 2013. Numerical modeling of low-frequency wave dynamics over a fringing coral reef. Coastal Engineering 73, $178-190$.

Wolanski, E., Delesalle, B., Dufour, V., Aubanel, A., et al., 1993. Modeling the fate of pollutants in the tiahura lagoon, moorea, french polynesia. In : 11th Australasian Conference on Coastal and Ocean Engineering : Coastal Engineering a Partnership with Nature; Preprints of Papers. Institution of Engineers, Australia, p. 583 . 